\title{
A Thermal Investigation of Dental Bleaching In Vitro
}

\author{
William Kabbach, ${ }^{1}$ Denise Maria Zezell, ${ }^{2}$ Thiago Martini Pereira, ${ }^{2}$ \\ Felipe Guimarães Albero, ${ }^{2}$ Victor Rene Grover Clavijo, ${ }^{1}$ \\ and Marcelo Ferrarezi de Andrade ${ }^{1}$
}

\begin{abstract}
Objective: Our goal was to investigate the surface temperature variations in the cervical region via infrared thermography, as well as the temperature within the pulp chamber via thermocouples, of mandibular incisors when subjected to dental bleaching using two different 35\% hydrogen peroxide gels, red (HP) and green (HPM), when activated by halogen light (HL) and LED light.

Background Data: Temperatures increases of more than $5.5^{\circ} \mathrm{C}$ are considered to be potentially threatening to pulp vitality, while those higher than $10^{\circ} \mathrm{C}$ can result in periodontal injury.

Materials and Methods: Tooth samples were randomly divided into four groups ( $\mathrm{n}=10$ each), according to the bleaching agent and catalyst light source used.

Results: Mean values and standard deviations of the temperature increases inside the pulp chamber in the HL groups were $4.4^{\circ} \pm 2.1^{\circ} \mathrm{C}$ with $\mathrm{HP}$, and $4.5^{\circ} \pm 1.2^{\circ} \mathrm{C}$ with $\mathrm{HPM}$; whereas in the groups using LED light, they were $1.4^{\circ} \pm 0.3^{\circ} \mathrm{C}$ for $\mathrm{HP}$, and $1.5^{\circ} \pm 0.2^{\circ} \mathrm{C}$ for HPM. For the root surfaces, the maximum temperature increases in the groups irradiated with $\mathrm{HL}$ were $6.5^{\circ} \pm 1.5^{\circ} \mathrm{C}$ for $\mathrm{HP}$, and $7.5^{\circ} \pm 1.1^{\circ} \mathrm{C}$ with $\mathrm{HPM}$; whereas in the groups irradiated with LED light, they were $2.8^{\circ} \pm 0.7^{\circ} \mathrm{C}$ with HP, and $3^{\circ} \pm 0.8^{\circ} \mathrm{C}$ with HPM. There were no statistically significant differences in pulp and surface temperature increases between the groups using different gels, although the mean temperature increases were significantly higher for the groups irradiated with HL when compared with those irradiated with the LED light ( $p<0.05$ with Tukey's test).

Conclusion: LED light may be safe for periodontal and pulp tissue when using this method, but HL should be used with care.

\section{Introduction}

$\mathrm{T}$ HE BLEACHING PROCEDURE has been enhanced by the development of new technologies, and this helps patients to obtain more immediate results. This technique requires the use of bleaching agents such as hydrogen peroxide, at concentrations ranging from $30-50 \% .{ }^{1,2}$ These products may be used in association with a light and/or heat source. ${ }^{3,4}$ The aim of the use of these energy sources is to accelerate the degradation of hydrogen peroxide, as well as to provide more effective results in a shorter time. 5,6

In order to choose irradiation parameters for these clinical applications, the fluences used must be safe for the vitality of the pulp and periodontal tissues. ${ }^{7,8}$ Dental pulp is highly vascularized and its viability may be compromised by thermal injury transmitted through the enamel and dentin. ${ }^{9}$ Previous studies have indicated that temperature increases of more than $5.5^{\circ} \mathrm{C}$ can be potentially threatening to pulp vitality, and increases of more than $16^{\circ} \mathrm{C}$ can result in

complete pulpal necrosis. ${ }^{10}$ Furthermore, the heat generated by the different light sources used in dental bleaching may also increase temperatures around the periodontal ligament. During the bleaching procedure, crown irradiation provides heat transmission toward the cervical region, which consequently heats periodontal tissues. If this results in temperature increases of more than $10^{\circ} \mathrm{C}$, there may be periodontal injury. ${ }^{11,12}$ To minimize these increases, dentists rely on the application of a pigmented bleaching agent in order to restrict the heat generated by the light absorption to the superficial gel layer. ${ }^{13,14}$ Therefore, investigating heat generation during light-activated bleaching is the first step when choosing the light parameters to use for clinical applications. 7,15

The objective of the present study was to evaluate the surface temperature variations in the root, as well as the temperatures within the pulp chamber of human mandibular incisors when submitted to dental bleaching with 35\% hydrogen peroxide, associated with two energy sources: halo-
\end{abstract}

\footnotetext{
${ }^{1}$ Restorative Dentistry Department, Universidade Estadual Paulista, Araraquara, and ${ }^{2}$ Laser and Application Center, Energy and Nuclear Research Institute, São Paulo, Brazil.
} 
Table 1. Thermal Properties of Human Teeth

\begin{tabular}{lccc}
\hline & Diffusivity $\left(\mathrm{m}^{2} / \mathrm{sec}\right)$ & Specific heat $\left(\mathrm{J} / \mathrm{g}{ }^{\circ} \mathrm{C}\right)$ & Thermal conductivity $\left(\mathrm{W} / \mathrm{cm}{ }^{\circ} \mathrm{C}\right)$ \\
\hline Enamel & $2.27 \times 10^{7}$ & 0.71 & $9.34 \times 10^{-3}$ \\
Dentin & $1.92 \times 10^{7}$ & 1.59 & $5.69 \times 10^{-3}$ \\
Water & $1.3 \times 10^{7}$ & 4.18 & $5.61 \times 10^{-3}$ \\
\hline
\end{tabular}

Adapted from references 21 and 22.

gen light (HL) and LED light. We sought to find a protocol for light-activated bleaching of the teeth that results in temperature variations that do not injure the periodontal or pulp tissue.

\section{Materials and Methods}

After approval by the Ethics Commission, 40 human mandibular permanent incisors were selected, cleaned, and stored in $0.5 \%$ chloramine for $7 \mathrm{~d}$ for disinfection. As the aim of the present study was to evaluate temperature increases generated during light-activated bleaching, the teeth were submitted to a process of accelerated darkening, accomplished by use of a staining mixture that consisted of equal parts of black tea, dry red wine, cola, pipe tobacco, and artificial saliva, as did Sulieman et al. ${ }^{16}$ using a technique modified by Guimarões et al. ${ }^{17}$ The teeth were mixed with the staining mixture and subjected to thermocycling for $1000 \mathrm{cy}$ cles in alternating baths at $5^{\circ} \mathrm{C}$ and $55^{\circ} \mathrm{C}$. Afterwards, the teeth were kept immersed in the staining mixture in an oven at $37^{\circ} \mathrm{C}$ for seven more days. Next the stained teeth were subjected to coronal polishing to remove superficial enamel stains. This was performed with a Robinson brush in a lowspeed handpiece, using a pumice and water paste.

The teeth were darkened from $3 \pm 2$ to $15 \pm 1$ on the Vita Lumin Shade Guide scale (Vita Zahnfabrik H. Rauter GmbH \& Co., Bäd Sackingen, Germany). This was done because the highest temperatures are reached during light-activated bleaching of dark teeth with low mass and thin walls.

For the bleaching process, we used two 35\% hydrogen peroxide (HP) gels: Whiteness HP (HP; FGM, Joinvile, Brazil) and Whiteness HP Maxx (HPM; FGM). Initially, the HP gel is red and it gradually becomes colorless, whereas the HPM gel is green and becomes a lighter shade of green when activated by light energy. We used two different energy sources: a halogen light (HL) with an intensity of 400 $\mathrm{mW} / \mathrm{cm}^{2}$ and wavelength of 400-500 nm (Optilight Plus; Gnatus, Ribeirão Preto, Brazil), and an LED light with an intensity of $350 \mathrm{~mW} / \mathrm{cm}^{2}$ and wavelength of 460-480 nm (Ultra Blue IV; DMC, São Carlos, Brazil).

After they were artificially darkened, the teeth were randomly divided into four groups ( $\mathrm{n}=10$ each), according to the bleaching agent and the activating light source used.

- Group 1: Teeth bleached with HP activated by HL.

- Group 2: Teeth bleached with HPM activated by HL.

- Group 3: Teeth bleached with HP activated by LED.

- Group 4: Teeth bleached with HPM activated by LED.

\section{Spectral absorption of the bleaching agents}

The absorption spectra of the bleaching gels was determined with the use of a temporal double-beam absorption spectrometer (USB650-Red Tide; Ocean Optics, Dunedin, FL, USA), calibrated in the spectral range from 400-950 nm, with a resolution of $2 \mathrm{~nm}$. An integration time of $60 \mathrm{msec}$ was used, and eight readings were taken for each curve of the sample, with absorption curves taken every $60 \mathrm{sec}$; the resulting spectrum was the mean of these eight readings. The spectra were normalized for optical density via use of an empty cube with an optical path of $0.1 \mathrm{~mm}$ as reference; then the samples to be tested were put in its place for analysis.

\section{Temperature monitoring}

The temperatures were recorded in real-time using two different methods. Infrared thermographic imaging allowed surface temperature monitoring, and thin thermocouples allowed the temperatures inside the pulp chamber to be monitored.

In order to measure the temperature in the pulp region during the bleaching procedure, a 125- $\mu \mathrm{m}$-thick type-K thermocouple (chromel-alumel ; Omega Engineering, Stamford, CT, USA), with a response time of $0.1 \mathrm{sec}$ and sensitivity of $0.1^{\circ} \mathrm{C}$ was introduced into each specimen via the apical foramen, so that the thermocouple's edge was aligned with the highest part of the pulp chamber. This required that the pulp chambers and root canals of all specimens be chemically and mechanically adapted. For this purpose we used a no. 2 Largo bur, $0.9 \mathrm{~mm}$ in diameter (Maillefer, Ballaigues, Switzerland), in a low-speed handpiece under constant irrigation with $1 \%$ sodium hypochlorite (Halex Istar, Goiânia, Brazil). After this step, a radiograph was made of each specimen to verify that the Largo bur had reached the pulp chamber. ${ }^{18,19}$ Using a hypodermic needle, the canals were filled with black stain diluted in a ratio of $0.1 \mathrm{~mL}: 30 \mathrm{~mL}$ of distilled deionized water. ${ }^{20}$ This is a standard procedure to ensure good contact between the thermocouple's tip and the area to be evaluated, in this case to assess the mean thermal conductivity in the highest portion of the pulp chamber, and to determine if temperatures there were equal to or higher than those seen in the pulp (Table 1). After the thermocouple was introduced, the root apices were sealed with composite resin (Filtek Z250; 3M, St. Paul, MN, USA). The samples were $x$-rayed once more to ensure that the junction was in contact with the buccal wall.

The temperature changes were monitored with an infrared thermographic camera using a quantum well infrared photodetector (SC 3000; Boston, MA) with a sensitivity of $0.01^{\circ} \mathrm{C}$ and response time of $0.01 \mathrm{sec}$. The camera was calibrated considering the dentin emissivity to be 0.91 within the temperature range of $20-100^{\circ} \mathrm{C}$, with data acquisition at $60 \mathrm{~Hz}$, with the ambient temperature stabilized at $20^{\circ} \mathrm{C}$ for $2 \mathrm{~h}$ before and during the experiment, at a distance of 0.1 meter between the sample and the camera, and with the ambient humidity at $46 \%$. 


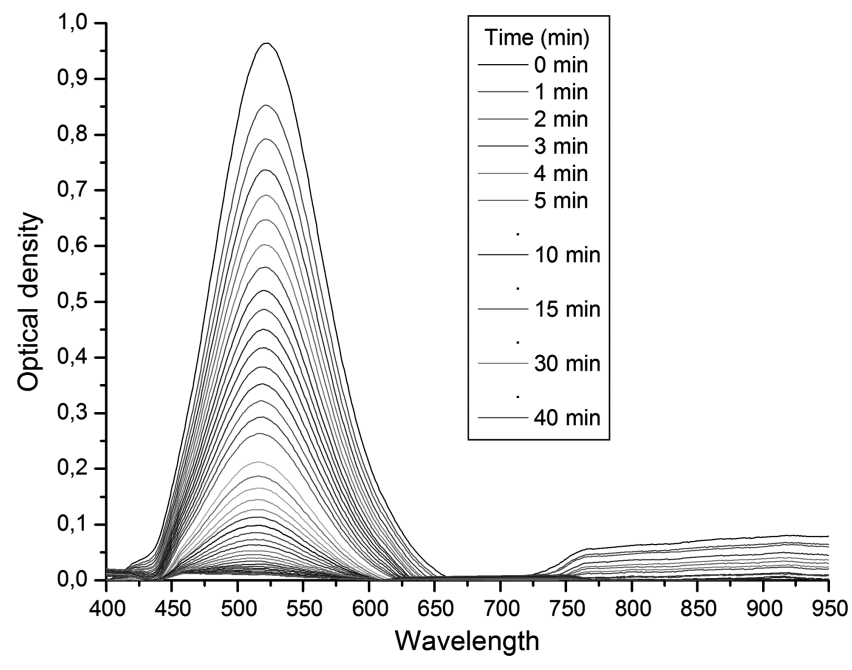

FIG. 1. Absorption spectrum of Whiteness HP gel (HP).

The data were processed using commercial software (ThermaCam Research 2001, Boston, MA) to determine the maximum temperature rise at the root. The temperature variation of each irradiation was calculated using computer software (Origin 7.0; OriginLab, Northampton, MA, USA).

\section{Exposure to the bleaching agent}

The teeth were placed in a thermal bath (Precision Scientific Co., Chicago, IL, USA) with water at $37^{\circ} \pm 1^{\circ} \mathrm{C}$, to reproduce the temperature conditions found in the oral cavity during irradiation, as well as to improve the transmission of the heat generated during the test.

The bleaching agent was mixed until a gel consistency was reached, using a ratio of 3 drops $(0.3 \mathrm{~mL})$ of hydrogen peroxide to 1 drop $(0.1 \mathrm{~mL})$ of thickening agent, according to the instructions supplied by the manufacturer. The gel was applied over the crown buccal surface of each specimen, in a layer approximately $1.0 \mathrm{~mm}$ thick. The gel was left on the enamel surface for $1 \mathrm{~min}$ after application. This period was suggested by the manufacturer to allow the bleaching agent to penetrate into the tooth's structure.

In order to standardize and maintain a distance of $5 \mathrm{~mm}$ between the activating light sources and the teeth, the appliances were fixed to an optical mount (Optron, Campinas, Brazil), and the distance was measured with a pachymeter (Mitutoyo, Suzano, Brazil). The measurements taken with the thermocouple were made with an acrylic device, in order to maintain the vertical position of the tooth in relation to the water surface, to assure that the entire root remained submerged, and to expose the tooth's buccal surface to the activating light source. For the measurements with the thermographic camera, the tooth was fixed horizontally in a thermal bath with the root's buccal aspect turned upwards, out of the water, allowing the images to be captured by the camera.

The light exposure times were determined according to the manufacturer's recommendations: $40 \mathrm{sec}$ for the HL, and 3 min for the LED.

\section{Results}

The absorption spectra can be seen in Figs. 1 and 2. For the HP gel there is one peak at $522 \mathrm{~nm}$ with $95 \mathrm{~nm}$ of full weight of half maximum (FWHM), and there is another band between 750 and $950 \mathrm{~nm}$ (complete decay is not seen due to the diffraction grade we used). For the HPM gel the first peak is at $525 \mathrm{~nm}$, with a FWHM of $100 \mathrm{~nm}$, and the longer the time, the longer the wavelength this peak displaces towards, reaching $600 \mathrm{~nm}$, but at an optical density well below the initial one. A very broad band can also be seen, as in the HP gel, starting at $750 \mathrm{~nm}$ and ending around $950 \mathrm{~nm}$.

The temperature was monitored by both the thermocouple and the thermographic camera in real time, during the bleaching procedure itself and for $20 \mathrm{sec}$ afterwards. Next, the data collected were submitted to both analysis of variance (ANOVA) and Tukey's test.

The means and standard deviations of the temperature increases within the pulp chambers in the HL groups (groups 1 and 2 ) were $4.4^{\circ} \pm 2.1^{\circ} \mathrm{C}$ for $\mathrm{HP}$, and $4.5^{\circ} \pm 1.2^{\circ} \mathrm{C}$ for $\mathrm{HPM}$; whereas in the groups that used the LED light (groups 3 and 4 ), the temperature variations were $1.4^{\circ} \pm 0.3^{\circ} \mathrm{C}$ for $\mathrm{HP}$, and $1.5^{\circ} \pm 0.2^{\circ} \mathrm{C}$ for HPM. At the root surface, the temperature variations in the groups irradiated with the HL (groups 1 and 2) were $6.5^{\circ} \pm 1.5^{\circ} \mathrm{C}$ for $\mathrm{HP}$, and $7.5^{\circ} \pm 1.1^{\circ} \mathrm{C}$ for $\mathrm{HPM}$; while in the groups irradiated with the LED light (groups 3 and 4 ), the temperature variations were $2.8^{\circ} \pm 0.7^{\circ} \mathrm{C}$ for $\mathrm{HP}$, and $3^{\circ} \pm 0.8^{\circ} \mathrm{C}$ for HPM (Fig. 3).

The mean temperatures both at the root surfaces and within the pulp chambers showed no statistically significant increases between the groups using the two types of gels $(p<0.05)$. The mean temperature increases were significantly higher for the groups irradiated with the HL (groups 1 and 2 ) compared to those irradiated with the LED (groups 3 and 4$)(p<0.05)$.

\section{Discussion}

Although light interacts with the gel during bleaching, there is a possibility that the heat will propagate and reach the pulp and periodontal tissue. The mechanism of heat conversion depends directly on the tissue constituents and the irradiation wavelength used. The tooth absorption coefficient is low for the wavelengths used in this study (400< $\lambda<500 \mathrm{~nm}$ ), thus scattering predominates over absorption. ${ }^{23}$ This leads to photons being absorbed far away from the irradiated surface. According to the modified Beer-Lam-

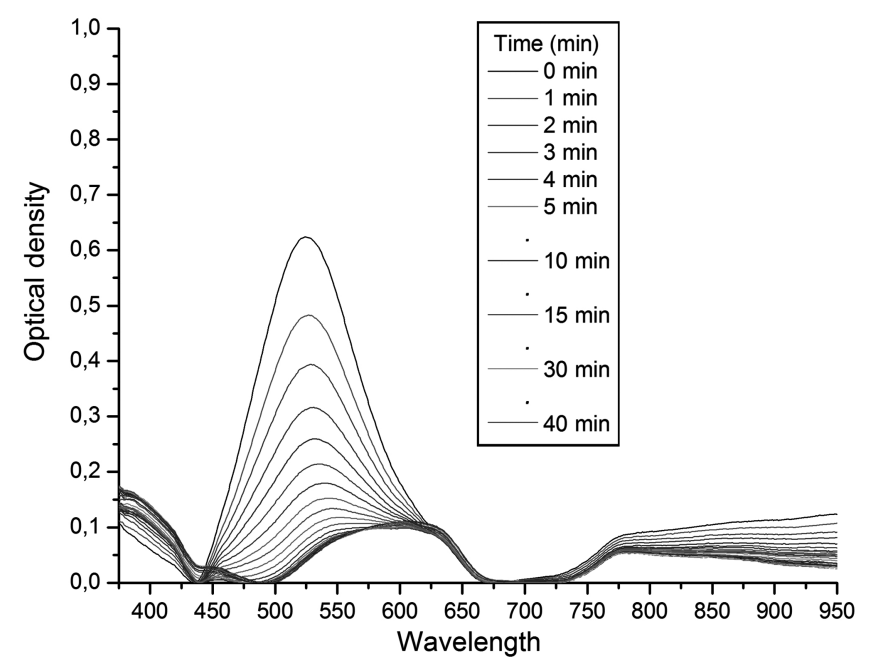

FIG. 2. Absorption spectrum of Whiteness HP Maxx (HPM). 


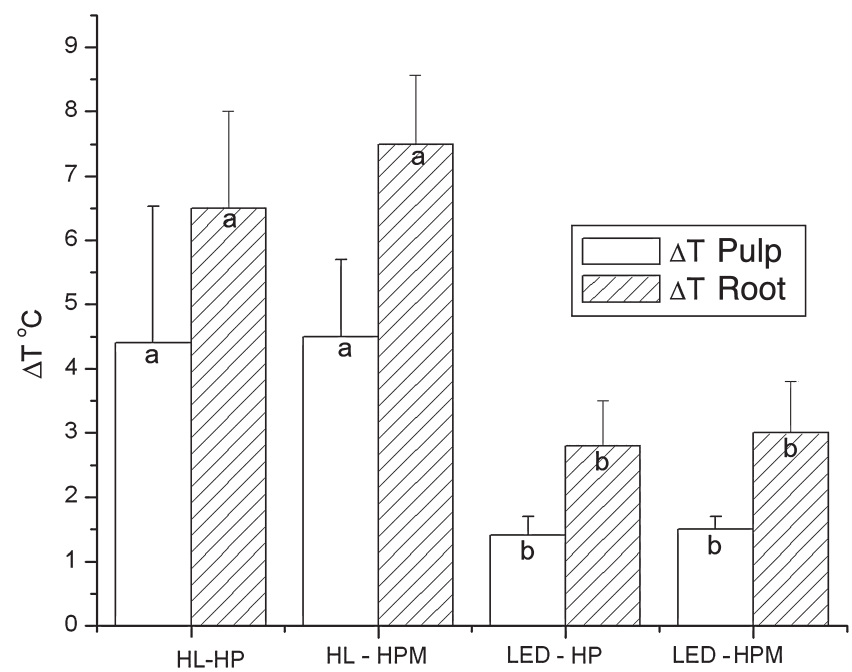

FIG. 3. Maximum temperature increases and standard deviations for the root surfaces and within the pulp chambers. Bars with different letters were statistically significantly different by Tukey's test $(p<0.05)$.

bert law and diffusion theory, the light intensity exponentially decreases in deeper layers of tissue; thus the resulting temperature at the surface is higher than are the internal temperatures. ${ }^{19}$ Nevertheless, the absorption of the scattered photons in deeper layers can result in temperature rises that are harmful to the pulp and periodontal tissue. For all these reasons, it is necessary to know the estimated temperature rise that occurs under a given set of parameters, before undertaking any clinical applications.

The low thermal diffusivity value of dental tissues (Table $1)$, which is defined as the thermal conductivity divided by the product of the density and heat capacity, ${ }^{22}$ is the parameter that characterizes the transient temperature change within a material when the material is exposed to changes in temperature. Thus, it is an important factor to know to protect dental tissues against thermal shock. ${ }^{24}$ Some studies $^{3,10,14}$ that used different teeth for thermal investigations mention that small teeth are more susceptible to heat, therefore we choice to use mandibular incisors, which are the smallest teeth found in human dentition. The results obtained in this study could be safety extrapolated to other types of teeth, if the same operating conditions were used.

Coloring matter is added to bleaching gels not only for the purpose of increasing light absorption, but also as an indicator of reaction, because soon after mixing the gel has a intense red color for the HP gel and green for the HPM gel,15,25 which over the course of the treatment lightens until the product becomes completely colorless. When comparing the activity of the gels under noncoherent light, HL at a wavelength from 400-500 $\mathrm{nm}$ and LED at a wavelength from 460-480 nm, we observed that these light sources were absorbed well by the two bleaching gels in the first few minutes of treatment, and that their absorption diminished as time passed and the color became less intense.

No in vitro study can replicate the clinical environment completely. In vivo, the surrounding tissues, which have much lower thermal conductivity than air, together with blood flow, constitute potential heat sinks. Thus, the thermal energy also dissipates more rapidly in vivo than in vitro be- cause of the circulation of blood in adjacent structures. ${ }^{26}$ The present study showed that the medians of temperature variation did not exceed $10^{\circ} \mathrm{C}$ in any of the experimental groups. The maximum mean temperature variation between the irradiated samples was $7.5^{\circ} \pm 1.1^{\circ} \mathrm{C}$, but with the use of the $\mathrm{HL}$, the medians of temperature variation were closer to $5.5^{\circ} \mathrm{C}$, with the maximum mean being $4.4^{\circ} \pm 2.1^{\circ} \mathrm{C}$. For clinical use care must be taken when performing these procedures, perhaps by reducing the light irradiation time.

It was evident that the LED light source had lower temperature increases for both the pulp and root surfaces and for both types of the gels we evaluated, compared to the HL source. These results are in agreement with the results obtained by Eldeniz et al., ${ }^{14}$ who evaluated intrapulpal temperatures during the bleaching procedure activated by highintensity $\mathrm{HL}\left(850 \mathrm{~mW} / \mathrm{cm}^{2}\right)$, conventional HL $(450$ $\left.\mathrm{mW} / \mathrm{cm}^{2}\right)$, LED light $\left(380 \mathrm{~mW} / \mathrm{cm}^{2}\right)$, and diode laser light. In another study by Sulieman et al., ${ }^{3}$ they found that the temperature changes were lowest for light sources with low intensity (a plasma arc lamp at $650 \mathrm{~mW} / \mathrm{cm}^{2}$ ) compared to those seen with a high-intensity HL $\left(1000 \mathrm{~mW} / \mathrm{cm}^{2}\right)$. The low-intensity light provided by LED generates little heat, which results in lower temperature values compared to those of other types of activating light sources.

According to Baik et al., 27 the light emitted by LED light sources induces photochemical effects with only minimal thermal effects when interacting with dark pigments in dentin, thus enhancing the bleaching process. Since the bleaching agent, and not the dental structure itself, is heated by the light source, as a result the peroxide breaks down.

The presence of the bleaching gel between the activating light source and the tooth surface markedly reduces pulp temperature increases. ${ }^{3,14}$ Moreover, in order to prevent high temperature increases of dental structures, stains or photosensitive agents are added to the bleaching gel. Thus, the light energy and heat are concentrated in the bleaching gel, and this promotes breakdown of the hydrogen peroxide and hydrogen penetration. ${ }^{15}$

The temperature increase associated with light-activated bleaching can be minimized by reducing the illumination time, as well as via the use of certain substances in the gel that raise its energy absorption, thus decreasing heat transmission to the tooth itself. ${ }^{28}$ Green laser energy can be absorbed by rhodamine B red dye, and the manufacturers of such lasers claim that it is the best light source to use with red gel. ${ }^{25}$ However, there were no statistically significant differences seen between the bleaching gels. The HP is initially red and gradually becomes colorless, therefore blue light was well absorbed; and for the HPM, which is green and becomes a lighter shade of green with use, red light would be more readily absorbed than would blue light. In this study, since the two light sources were both in the blue region of the spectrum, the HP gel showed the least temperature increase.

The ideal bleaching treatment must provide acceptable results, without causing injury to dental tissues. ${ }^{29}$ Therefore, it is useful to perform a thorough analysis of the outcomes of the available studies with regard to the potential adverse effects of bleaching therapy.

\section{Conclusion}

The results of this study showed that the use of different bleaching gels did not statistically significantly alter the 
mean temperature increases seen within the pulp chambers and root surfaces of the incisors we tested. These results suggest that though the LED light source appears to be safe for periodontal and pulp tissue when using this method, the use of a halogen light source requires more care.

\section{Disclosure Statement}

No competing financial interests exist.

\section{References}

1. Barghi, N. (1998). Making a clinical decision for vital tooth bleaching: at-home or in-office? Compend. Contin. Educ. Dent. 19, 831-838.

2. Goldstein, R.E. (1997). In-office bleaching: Where we came from, where we are today. J. Am. Dent. Assn. 128, 11S-15S.

3. Sulieman, M., Addy, M., and Rees, J.S. (2005). Surface and intra-pulpal temperature rises during tooth bleaching: An in vitro study. Br. Dent. J. 199, 37-40.

4. Sulieman, M., MacDonald, E., Rees, J.S., and Addy, M. (2005). Comparison of three in-office bleaching systems based on 35\% hydrogen peroxide with different light activators. Am. J. Dent. 18, 194-197.

5. Hall, D.A. (1991). Should etching be performed as a part of a vital bleaching technique? Quintessence Int. 22, 679-686.

6. Nakamura, T., Saito, O., Ko, T., and Maruyama, T. (2001). The effects of polishing and bleaching on the colour of discoloured teeth in vivo. J. Oral Rehabil. 28, 1080-1084.

7. Goodis, H.E., Fried, D., Gansky, S., Rechmann, P., and Featherstone, J.D.B. (2004). Pulpal safety of $9.6 \mathrm{~nm}$ TEA $\mathrm{CO}_{2}$ laser used for caries prevention. Lasers Surg. Med. 35, 104-110.

8. Nammour, S., Kowaly, K., Powell, G.L., Van Reck, J., and Rocca, J.P. (2004). External temperature during KTP$\mathrm{Nd}$ :YAG laser irradiation in root canals: An in vitro study. Lasers Med. Sci. 19, 27-32.

9. Nyborg, H., and Brännström, M. (1968). Pulp reaction to heat. J. Prosthet. Dent. 19, 605-612.

10. Zach, L., and Coeh, G. (1965). Pulp response to externally applied heat. Oral Surg. Oral Med. Oral Pathol. 19, 515-530.

11. Eriksson, A., Albrektsson, T., Grane, B., and McQueen, D. (1982). Thermal injury to bone. A vital-microscopic description of heat effects. Int. J. Oral Surg. 11, 115-121.

12. Ramsköld, L.O., Fong, C.D., and Strömberg, T. (1997). Thermal effects and antibacterial properties of energy levels required to sterilize stained root canals with an Nd:YAG laser. J. Endodont. 23, 96-100.

13. de Andrade, L.E.H., Lizarelli, R.F.Z., Pelino, J.E.P., Bagnato, V.S., and de Oliveira, O.B. (2007). Enamel caries resistance accidentally irradiated by the Nd:YAG laser. Laser Phys Lett. 4, 457-463.

14. Eldeniz, A.U., Usumez, A., Usumez, S., and Ozturk, N. (2005). Pulpal temperature rise during light-activated bleaching. J Biomed. Mater. Res. 72, 254-259.
15. Buchalla, W., and Attin, T. (2007). External bleaching therapy with activation by heat, light or laser-A systematic review. Dent. Mater. 23, 586-596.

16. Sulieman, M., Addy, M., and Rees, J.S. (2003). Development and evaluation of a method in vitro to study the effectiveness of tooth bleaching. J. Dent. 31, 415-422.

17. Guimarões, J.D.A.M., Stolf, W.S.F., Silva, E. M., Zezell, D.M., and Eduardo, C.P. (2004). In vitro thermographic measurement in pulpal chamber during diode laser bleaching. Braz. Dent. J. 15, 94.

18. Ana, P.A.B., Miyakawa, W., and Zezell, D.M. (2007). Thermal analysis of teeth irradiated with Er,Cr:YSGG at low fluences. Laser Phys. Lett. 4, 827-833.

19. da Costa Ribeiro, A., Nogueira, G.E.C., Antoniazzi, J.H., Moritz, A., and Zezell, D.M. (2007). Effects of diode laser $(810 \mathrm{~nm})$ irradiation on root canal walls: Thermographic and morphological studies. J. Endodont. 33, 252-255.

20. Farhat, P.B.A.T., Zezell, D.M., Miyakawa, W., and Nogueira, G.E.C. (2004). Model of thermal and optical effect in dental pulp during neodymium and diode laser irradiation. Braz. Dent. J. 15, 90.

21. Pannas, A.J.Z., Terpiloxski, J., and Preikson, M. (2003). Investigation of the thermal diffusivity of human tooth hard tissue. Int. J. Thermophys. 24, 837-848.

22. Brown, W.S., Dewey, W.A., and Jacobs, H.R. (1970). Thermal properties of teeth. J Dent. Res. 49, 752-755.

23. Niemz, M. (1996). Laser Tissue Interactions: Fundamentals and Applications. Berlin: Springer.

24. Watts, D.C., McAndrew, R., and Lloyd, C.H. (1987). Thermal diffusivity of composite restorative materials. J. Dent. Res. 66, 1576-1578.

25. Walsh, L.J., Lui, J.Y., and Verheyen, P. (2004). Tooth discolouration and its treatment using KTP laser-assisted tooth whitening. J. Oral Applic. 4, 21-27.

26. Saunders, E.M. (1990). In vivo findings associated with heat generation during thermomechanical compaction of guttapercha. 1. Temperature levels at the external surface of the root. Int. Endodont. J. 23, 263-267.

27. Baik, J.W., Rueggeberg, F.A., and Liewehr, F.R. (2001). Effect of light-enhanced bleaching on in vitro surface and intrapulpal temperature rise. J. Esthet. Restorative Dent. 13, 370-378.

28. Luk, K., Tam, L., and Hubert, M. (2004). Effect of light energy on peroxide tooth bleaching. J. Am. Dent. Assn. 135, 194-201.

29. Tam, L.E., Lim, M., and Khanna, S. (2005). Effect of direct peroxide bleach application to bovine dentin on flexural strength and modulus in vitro. J. Dent. 33, 451-458.

Address reprint requests to: Dr. William Kabbach Rua Abel Giongo, 1936, Vila Nery CEP 13569-100 São Carlos, São Paulo, Brazil

E-mail: wkabbach@terra.com.br 